\title{
Methods for the formation and optimization of calendar plans for construction companies
}

\author{
Pavel Oleinik, Alexey Yurgaytis ${ }^{*}$, Galina Voronina $^{1}$ and Alisa Makarenko \\ Moscow State University of Civil Engineering, Yaroslavskoe shosse, 26, Moscow, 129337, Russia
}

\begin{abstract}
This article describes the methods of forming and optimizing the calendar plans of construction enterprises, their nature and applicability in different specific cases. The main types of schedules and schedules of planning of building processes and normative documents used in the formation of calendar plans are also described. In addition to existing and actively used methods for optimizing calendar plans, new directions for the development of optimization algorithms are described, which are just beginning to be introduced into building technologies.
\end{abstract}

\section{Introduction}

To monitor the actions of the participants in the construction process and the time of their implementation, a calendar plan is recreated, occupying a special place in the complex of planning and construction management tasks.

The calendar plan is a document in the structure of the construction project, which determines the timing of the work and their schedule. As part of the construction organization project (COP), a consolidated construction schedule is being developed, as part of the production work project (PWP), calendar work plans for individual facilities. Based on the data of the calendar plan, the progress of work is monitored and the work of the performers is coordinated. The deadlines, calculated in the calendar plan, are taken as a basis for more detailed data processing, for example, in weekly and daily schedules and shift tasks.

For the development of the calendar plan, the initial data are the working drawings, the data of construction surveys, information on material and technical resources and the regulatory deadlines for construction. In the preparation of calendar plans, the use of advanced production technology is envisaged; execution of construction by a flow method with the maximum co-ordination of works, uniform loading of the basic executors and uniform consumption of resources; compliance with the requirements of technical conditions and safety regulations.

\footnotetext{
*Corresponding author: aljurgaitis@gmail.com
} 


\section{Materials and Methods}

Calendar schedules are divided into four types [8 - 17], which differ among themselves depending on the tasks and the type of documentation, but they must be closely related to each other (Fig.1).

The consolidated schedule

The object schedule

$$
\begin{aligned}
& \text { Calendar } \\
& \text { plans } \\
& \text { (schedules) }
\end{aligned}
$$
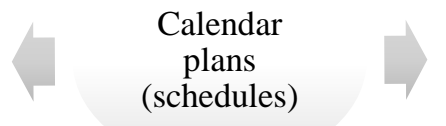

Hourly

(minute)

schedules

Working schedules

Fig. 1. Types of calendar plans (schedules)

- The consolidated schedule in the construction organization design determines the sequence of erection of objects, that is, the start and finish dates for the construction of each of the facilities, the amount of time for the preparatory period and all construction in general.

- The object schedule in the project of work execution determines the timeframe for each type of work on the facility from the beginning of construction to the time of commissioning.

- $\quad$ Working schedules are drawn up directly by the construction participants for a week, a month, several months. They have a fairly simplified form, but convey the actual situation at the construction site as accurately as possible. Planning for this method must be carried out throughout the construction period.

- Hourly (minute) schedules are compiled by developers of technological maps and workflow maps, they are well thought out, but, unfortunately, in many situations require adjustments based on their orientation to typical working conditions.

As for example, the network diagram (Fig. 2) is a model of the technological process of erecting a building or a complex of buildings. The advantage of this type of model is the ability to clearly identify the relationship between the types of work: what work should be done before the beginning of the previous one and the time required for it. 


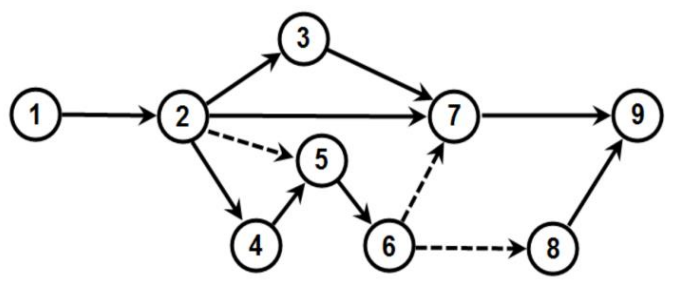

Fig. 2. Network timetable

Some normative documentation for scheduling are shown in table below (Table 1).

Table 1. Some normative documentation

\begin{tabular}{|l|l|}
\hline No & \multicolumn{1}{|c|}{ Normative documentation } \\
\hline 1. & $\begin{array}{l}\text { Set of norms and rules 3.01.01-85 "Organization of construction", including "Manual } \\
\text { for the development of construction projects and projects for the production of works } \\
\text { for civil engineering". }\end{array}$ \\
\hline 2. & $\begin{array}{l}\text { Set of norms and rules 1.04.03-85 "Norms of the duration of construction and } \\
\text { protection in the construction of enterprises of buildings and structures." }\end{array}$ \\
\hline 3. & $\begin{array}{l}\text { Set of norms and rules 12-01-2004 "Organization of construction" (instead of Set of } \\
\text { norms and rules 3.01.01.-85) }\end{array}$ \\
\hline 4. & $\begin{array}{l}\text { Set of rules 48.13330.2011 "Organization of construction" (updated version of Set of } \\
\text { norms and rules 12 01-2004) }\end{array}$ \\
\hline 5. & $\begin{array}{l}\text { Methodical documents in construction 12-81.2007 "Methodological recommendations } \\
\text { for the development and design of the construction organization and the project of } \\
\text { production work." }\end{array}$ \\
\hline
\end{tabular}

A calendar plan is an essential part of strategic planning. It demonstrates: what production facilities the enterprise has, how much work it can perform.

Under the contract of construction contractor the contractor undertakes, within the period established by the contract, to construct, on the instructions of the customer, a certain object or perform other construction work, and the customer undertakes to create the necessary conditions for the work to perform the contractor, to accept their result and pay the stipulated price.

In order to agree on the timing of the fulfillment of mutual obligations by the parties to the construction contract, various calendar plans and schedules are usually attached, which become constituent parts of the contract.

The method of scheduling helps to solve problems on two levels:

Level of production (contractor level)

- Solving the problems of organization of technical planning as part of the PWP

- The goal is to schedule the timeframe taking into account all production realities, the actual consumption of materials, supplies, technologies used, etc. Optimization at this level - bringing to the optimum of cost, manufacturability, material consumption of production

Level of customer

- Solving the problems of the investor at the stage of development by the general designer of the construction organization project.

- The goal is to determine the order of erection of objects, fthe start and end dates of each facility, the duration of the preparatory period and the entire construction in general. As a rule, a separate calendar schedule is drawn up for the preparatory period. Existing standards provide for the compilation in COP of calendar plans in 
cash, i.e. in thousand rubles. with distribution by quarters or years (for the preparatory period - by months).

During writing of this article, sources from the bibliographic list $[1-7,18]$ were used, in which methods for optimizing calendar plans were studied.

The formation of methods for solving practical problems is based on the definition:

- Optimization tasks, expressed as a criterion, the value of which indicates the preferences of one or other of the parameters being compared.

- Achievable performance criterion values that depend on limited resources, thereby reducing the possibility of improving efficiency.

\section{Pragmatic value}

Introduction of the results into practice

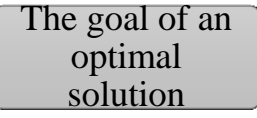

Goal model

Fig 3. The Pragmatic Direction of the Solution of Optimization Problems

Optimization models that serve to control an object or process are constructed to obtain the most effective results when changing control parameters.

The criterion of optimality is a technological characteristic that estimates the economy of work. There are simple and complex criteria for optimality. A simple criterion of optimality is used when it is necessary to determine the extremum of the objective function without specifying conditions on other quantities.

Table 2. Criterion for optimality.

\begin{tabular}{|c|l|l|}
\hline & \multicolumn{1}{|c|}{ A simple criterion for optimality } & A complex optimality criterion \\
\hline 1 & \multicolumn{1}{|c|}{2} & \multicolumn{1}{|c|}{3} \\
\hline Application & $\begin{array}{l}\text { If it is necessary to determine the } \\
\text { extremum of the objective function } \\
\text { without specifying conditions on other } \\
\text { quantities. Usually used in solving } \\
\text { particular optimization problems. }\end{array}$ & $\begin{array}{l}\text { If necessary, establish the } \\
\text { under incorrect conditions, } \\
\text { underimposed on a number of other } \\
\text { superiables and constraints. } \\
\text { variables }\end{array}$ \\
\hline
\end{tabular}

By quantity and quality of raw materials and products

$$
\text { on the terms of technology }
$$

For economic reasons

On protection of labor and environment

Fig. 4 The main limitations imposed for technological and economic reasons 
The main optimization problem is to find the extremum of the optimality function by various methods.

Table 3. To optimize the schedule, there are 3 mutually complementary methods

\begin{tabular}{|c|l|l|}
\hline No. & Method name & \multicolumn{1}{|c|}{ Method essence } \\
\hline 1 & \multicolumn{1}{|c|}{2} & \multicolumn{1}{c|}{3} \\
\hline 1 & $\begin{array}{l}\text { Formal } \\
\text { construction of } \\
\text { the critical path }\end{array}$ & $\begin{array}{l}\text { The task is critical if the shift in the calendar start of the work } \\
\text { causes a change in the project's finish date. All formal critical } \\
\text { tasks constitute the critical path of the project. }\end{array}$ \\
\hline 2 & $\begin{array}{l}\text { "Rocking" of } \\
\text { the calendar } \\
\text { plan }\end{array}$ & $\begin{array}{l}\text { The formal definition of a critical path in a number of cases leads } \\
\text { to dangerous errors, since it is not self-sufficient. To identify all } \\
\text { possible changes in the critical path, the "rocking" of the calendar } \\
\text { plan is applied. It consists in the fact that the duration of each task } \\
\text { varies in the range of 25-30\%, new connections are deleted and } \\
\text { introduced. If critical changes occur in the critical path, the } \\
\text { dependencies between the tasks are not set correctly and it } \\
\text { becomes necessary to check all the dependencies and reinstall } \\
\text { them. }\end{array}$ \\
\hline 3 & Expert analysis & $\begin{array}{l}\text { The final and most effective way to establish critical tasks. In } \\
\text { addition to the tasks obtained by the previous two methods, the } \\
\text { tasks that most contain the risk of delays are clarified. }\end{array}$ \\
\hline
\end{tabular}

Table 4. Recommended techniques

To check the duration of critical tasks and to offset the risks to deduce calendar reserves

Verify and establish the dependencies between critical tasks

Minimize the number of links by placing critical tasks between the points of key calendar events.

\section{Results and Discussion}

There are a number of modern optimization algorithms that, along with classical methods [18], are introduced into the construction industry, speeding up and facilitating scheduling.

One such method is the Microsoft Project software package, which develops calendar plans, which later need to be optimized.

Optimization occurs according to certain criteria, such as resources, terms, cost, etc., depending on what needs to be optimized. Microsoft Project offers a number of types of restrictions: 


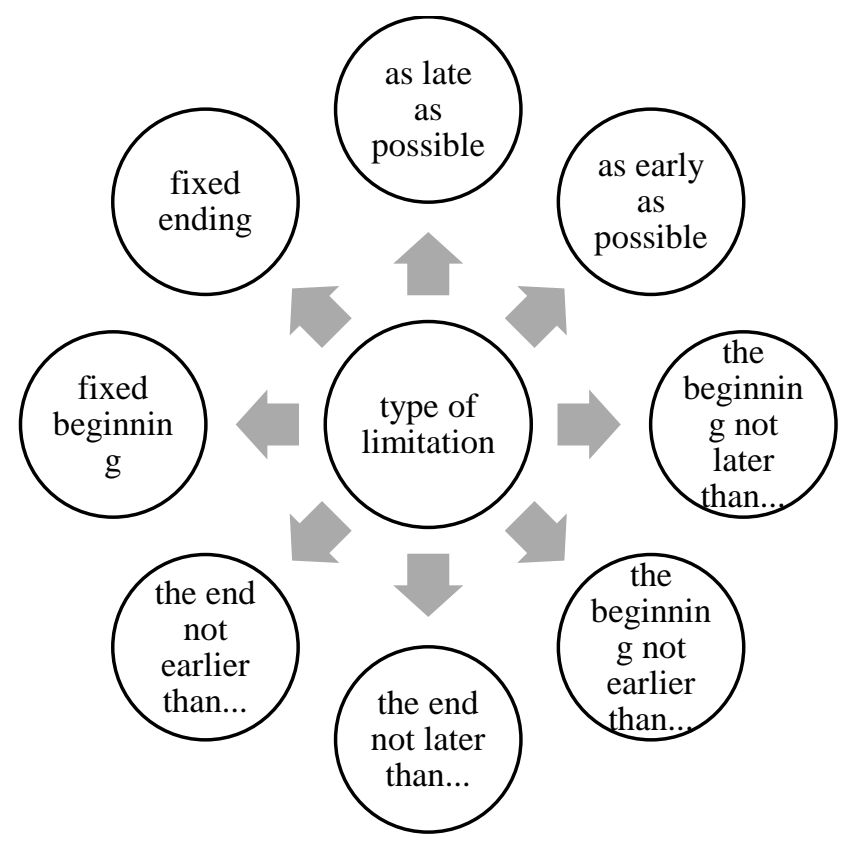

Fig. 5 Type of limitation

In the software complex, you can also, if necessary, compress the schedule, unload resources, manage the cost of the project and much more with various nuances of the project, taken into account in the settings.

A completely new approach to the process of planning the resource allocation of the production program of a construction enterprises is the following algorithm. First, we introduce the concept of capacity of a construction company - in this case, capacity will be identified with the value of the planned resource (labor) of a construction company for the implementation of projects of the production program (at the end of the year). The value of this resource (labor) will be constant, so the fundamental approach to the form of diagrams of the distribution of the resource field in time is obvious - the actual distribution of resources should be as close as possible to the constant value of the planned indicator. In this case, the final planned value of the resource size will take into account a certain correction for temporary disability, sick leave, vocations etc. (formula 1).

$$
\text { Rplan,in }=\text { Rplan } \pm \Delta R, \text { where }
$$

Rplan- the initial planned value obtained from the results of the analysis of the duration of the planning and financial departments of construction organizations and the analysis of organizational and technological documentation on the objects of production programs $\Delta R$ correction of the value of the resource,

$\Delta R \in[0,01 ; 3]$ (according to statistical data)

$$
\text { Rplan }=\text { Rth eor }, \text { where }
$$

The basic principle of construction of the developed algorithm is that the amount of labor resources for all objects of the production program in a specific cross-section of the resource schedule should be minimal. 


$$
\sum(\text { Rth eor } n 1-R f a c t) \rightarrow \min , \text { where }
$$

Rth eor - theoretical resource consumption by program objects, equal to the constant planned value;

$R f a c t$ - actual resource consumption by program objects;

$n$ - the number of objects of the production program in the range $\in[1 ; n]$

As a limitation of the optimization algorithm, the following condition applies:

$$
T \leq \text { Tdir, where }
$$

$T$ - total actual production time at the facility approved by the production program;

Tdir - the directive date for the execution of work at the facility in accordance with the construction contract.

\section{Conclusions}

The authors' developments in the field of optimizing the planning of construction production allow the use of new algorithms for the efficient allocation of resources among the program's construction sites. Thus, depending on the capacity of the organization, the technological specialization of the organization and the technological schemes for the construction of various facilities, the organizers of production and the heads of construction firms receive a tool for obtaining the optimal solution in the conditions of unpredictable adding objects to the production program of the enterprise. Together with the existing software systems and management decision support system, the methodology for distributing construction work (by own organization's resources or by subcontracting organizations) acquires a clear algorithmization to achieve a greater economic and technological effect of entering objects compared to fully heuristic or intuitive control methods.

\section{References}

1. P. Oleinik, A. Yurgaytis, Optimization of the annual construction program solutions (MATEC Web of Conferences, 117, 2017)

2. Dmitriy Topchiy, Anastasia Shatrova, Alexey Yurgaytis, Integrated construction supervision as a tool to reduce the developer's risks when implementing new and redevelopment projects (MATEC Web of Conferences, 193, 2018)

3. P. Oleinik, A. Yurgaytis, The method of forming solutions for non-critical activities in the preparation and optimization of the construction complex organizations' annual program (MATEC Web of Conferences 193, 2018)

4. M. Rogalska, W. Bozejko, Z. Hejducki, Time/cost optimization using hybrid evolutionary algorithm in construction project scheduling (Automation in Construction, 2008)

5. W. Bozejko, Z. Hejducki, M. Uchroński, M. Wodecki, Solving resource-constrained construction scheduling problems with overlaps by metaheuristic (Journal of Civil Engineering and Management, 2014)

6. W. Bozejko, Z. Hejducki, M. Wodecki Applying metaheuristic strategies in construction projects management (Journal of Civil Engineering and Management, 2012)

7. M. Rogalska, W. Bozejko, Z. Hejducki, M. Wodecki, Development of time couplings method using evolutionary algorithms (ISARC 2008 - Proceedings from the 25th International Symposium on Automation and Robotics in Construction, 2008) 
8. M. Rogalska, Z. Hejducki, Time buffers in construction process scheduling (Journal of Civil Engineering and Management, 2007)

9. Z. Hejducki, M. Rogalska, Shortening the realisation time of building projects with application of theory of constraints and critical chain scheduling (Journal of Civil Engineering and Management, 2005)

10.Z. Hejducki, Sequencing problems in methods of organizing construction processes (Engineering, Construction and Architectural Management, 2004)

11.Z. Hejducki, Scheduling model of construction activity with time couplings (Journal of Civil Engineering and Management, 2003)

12.Z. Hejducki, J. Mrozowicz, Stream methods of construction work organization: An introduction to the problem (Engineering, Construction and Architectural Management, 2001)

13. S.H. Han, M. Al-Hussein, S. Al-Jibouri, H. Yu, Automated post-simulation visualization of modular building production assembly line, Autom. Constr. 21 (2012)

14. H. Taghaddos, U. Hermann, S. AbouRizk, Y. Mohamed, Simulation-based multiagent approach for scheduling modular construction, (J. Comput. Civ. Eng. 28, 2012)

15.P.Y. Hsu, M. Aurisicchio, P. Angeloudis, Establishing outsourcing and supply chain plans for prefabricated construction projects under uncertain productivity (International Conference on Computational Logistics 2017, Southampton, UK, October 18-20, 2017)

16.P.Y. Hsu, M. Aurisicchio, P. Angeloudis, Investigating schedule deviation in construction projects through root cause analysis, (Proc. Comput. Sci. 121, 2017)

17. Albert Ponsteena, Rob J. Kusters Classification of Human- and Automated Resource Allocation Approaches in Multi-Project Management (Procedia - Social and Behavioral Sciences 194, 2015) 